\title{
Biocatalytic synthesis of highly ordered degradable dextran-based hydrogels
}

\author{
Lino Ferreira $^{\mathrm{a}, 1}$, Maria H. Gil ${ }^{\mathrm{a}}$, Antonio M.S. Cabrita ${ }^{\mathrm{b}}$, Jonathan S. Dordick ${ }^{\mathrm{c}, *}$ \\ ${ }^{a}$ Departamento de Engenharia Química, Universidade de Coimbra, Pinhal de Marrocos, 3030 Coimbra, Portugal \\ ${ }^{\mathrm{b}}$ Instituto de Patologia Experimental, Faculdade de Medicina, Universidade de Coimbra, Portugal \\ ${ }^{\mathrm{c}}$ Department of Chemical and Biological Engineering, Rensselaer Polytechnic Institute, 102 Ricketts Bldg., Troy, New York 12180, USA
}

Received 26 June 2004; accepted 18 November 2004

\begin{abstract}
We have prepared unique macroporous and ordered dextran-based hydrogels using a single-step biocatalytic transesterification reaction between dextran and divinyladipate in neat dimethylsulfoxide. These hydrogels show a unimodal distribution of interconnected pores with average diameters from 0.4 to $2.0 \mu \mathrm{m}$ depending on the degree of substitution. In addition, the hydrogels show a higher elastic modulus for a given swelling ratio than chemically synthesized dextran-based hydrogels. In vivo studies in rats show that the hydrogel networks are degradable over a range of time scales from 5 to over 40 days, and possess good biocompatibility, as reflected in only a mild inflammatory reaction and minor fibrous capsule formation during the time-frame of subcutaneous implantation. These combined properties may offer competitive advantages in biomedical applications ranging from tissue engineering to controlled drug delivery.
\end{abstract}

(C) 2004 Elsevier Ltd. All rights reserved.

Keywords: Enzyme; Dextran; Hydrogel; Cross-linking; Biodegradation

\section{Introduction}

The site-selective proliferation of cells and the modulation of cellular function at implantable sites require the controlled release of biologically active macromolecules, including peptides, proteins, and DNA [1-3]. These molecules must be incorporated into biocompatible, and ultimately erodable/biodegradable, matrices that provide for useful materials properties while maintaining biologically relevant functionality. This includes potential use as scaffolds to deliver cells to specific anatomic sites, create and maintain a space for tissue development, and guide tissue formation before being degraded [4]. These desired properties have served

\footnotetext{
${ }^{*}$ Corresponding author. Tel.: + 15182762899 ; fax: +15182762207 .

E-mail address: dordick@rpi.edu (J.S. Dordick).

${ }^{1}$ Current address: INEB-Instituto de Engenharia Biomédica, Laboratório de Biomateriais, Rua do Campo Alegre 823, 4150-180 Porto, Portugal.
}

as the driving force for the use of a wide range of synthetic matrices that are biocompatible and erodable/ biodegradable, including aliphatic polyesters, such as poly(glycolic acid) (PGA) and poly(lactic acid) (PLA), polyanhydrides, and the use of natural matrices such as collagen, among others $[5,6]$. However PGA and PLA are stiff materials, which make them in general less suitable as matrices for soft tissue engineering [6], while bovine collagen has potential risks for disease transmission [7].

Polysaccharide hydrogels, particularly those based on dextran, may be an alternative to the aforementioned polymers especially for soft tissue engineering applications. These glucose-based polymers are available in a wide range of molecular weights and contain a high density of hydroxyl groups that make the polymers highly hydrophilic and capable of being further functionalized chemically or enzymatically. Dextran is also biocompatible and can be degraded through the action of dextranases in various organs in the human body, 
including liver, spleen, kidney, and colon [8]. Unfortunately, hydrogels prepared from complex precursors such as sugars and polysaccharides typically consist of heterogeneous microstructures with variable physicochemical properties $[9,10]$. This is particularly severe for hydrogels that contain a wide pore size distribution resulting in variable release profiles of large biomolecules and non-uniform materials properties leading to poor degradability $[11,12]$. Furthermore, in some cases, hydrogels may promote fibrous capsule formation upon implantation in vivo precluding their general use as scaffolds and implantable drug delivery systems [13-15].

In the present work we describe a biocatalytic strategy to obtain unique macroporous and ordered dextranbased hydrogels, which involves a single-step transesterification reaction between dextran and divinyladipate (DVA) in neat dimethylsulfoxide (DMSO). This reaction is highly surprising given the strong denaturing capacity of DMSO, yet regioselective dextran acylation and gel formation ensues. The resulting hydrogels are degradable at physiologic $\mathrm{pH}$, do not form substantial fibrous capsule when implanted subcutaneously in rats, and have superior mechanical properties to dextranbased hydrogels obtained chemically. The biocatalytic route, therefore, leads to a novel material that cannot be synthesized using more traditional chemical techniques.

\section{Materials and methods}

\subsection{Materials}

The protease (EC 3.4.21.62) from Bacillus subtilis (Proleather FG-F) was a gift from Amano Enzyme Ltd. (Troy, VA). The other enzymes used in this work were commercially available and the suppliers are listed in Supplementary Material Table 1. DVA was purchased from TCI America (Portland, OR). Dextran (from Leuconostoc mesenteroides; $\quad M_{\mathrm{n}}=39,940$, $\left.M_{\mathrm{w}}=70,000 \mathrm{Da}\right)$ was obtained from Fluka Chemie AG (Buchs, Switzerland). 4-Dimethylaminopyridine (4DMAP) was purchased from Aldrich (Milwaukee, WI). Solvents were dried over molecular sieves for at least $24 \mathrm{~h}$ prior to use to remove residual water. The water content in DMSO was measured by Karl-Fischer titration and was below $0.06 \%(\mathrm{v} / \mathrm{v}) \mathrm{H}_{2} \mathrm{O}$. Other chemicals and solvents were of the highest grade commercially available.

\subsection{Enzyme screening for the transesterification reaction of dextran with DVA}

The enzymes were "pH-adjusted" prior to use, in the presence of $20 \mathrm{~mm}$ phosphate buffer at $\mathrm{pH} 8.0$ (Proleather, Protease $\mathrm{S}$, and subtilisin Carlsberg) or at $\mathrm{pH}$ 7.5 (Proteases A, N, and P, and Lipases A, AY, M, PS, and Porcine Pancreas). After being flash-frozen in liquid nitrogen, the samples were lyophilized on a Labconco freeze-drier (Labconco Corp., Kansas City, MO) for $48 \mathrm{~h}$. Proleather thermally deactivated or inhibited by PMSF were prepared as described previously [16]. Reactions were performed in $15 \mathrm{~mL}$ of anhydrous DMSO containing dextran $M_{\mathrm{w}}=70 \mathrm{kDa}(1 \mathrm{~g}), 0.20 \mathrm{M}$ DVA and $300 \mathrm{mg}$ of "pH-adjusted" enzymes (except for subtilisin Carlsberg, which was employed at $150 \mathrm{mg}$ ). The reaction mixtures were shaken at $50{ }^{\circ} \mathrm{C}$ and $250 \mathrm{rpm}$ for $72 \mathrm{~h}$ (except $48 \mathrm{~h}$ for Proleather FG-F and lipases $\mathrm{AY}$ and PS).

\subsection{Proleather FG-F catalyzed synthesis of dextran- $D V A$}

Dextran $(1 \mathrm{~g}, 1.0 \mathrm{~mm})$ and different concentrations of DVA (0.041-0.41 M) were dissolved in $15 \mathrm{~mL}$ DMSO

Table 1

Network properties of dextran-DVA hydrogels obtained either chemically or enzymatically

\begin{tabular}{|c|c|c|c|c|c|c|}
\hline \multirow{2}{*}{$\begin{array}{l}\text { Initial molar ratio of } \\
\text { DVA to dextran }(\%)\end{array}$} & \multicolumn{3}{|c|}{ Biocatalytic hydrogels ${ }^{\mathrm{a}}$} & \multicolumn{3}{|c|}{ Chemical hydrogels $^{\mathrm{b}}$} \\
\hline & $\operatorname{DS}(\%)^{\mathrm{b}}$ & $\mathrm{DS}_{\text {monoester }}(\%)^{\mathrm{c}}$ & $\operatorname{DS}_{\text {diester }}(\%)^{\mathrm{d}}$ & $\operatorname{DS}(\%)^{\mathrm{b}}$ & $\mathrm{DS}_{\text {monoester }}(\%)^{\mathrm{c}}$ & $\operatorname{DS}_{\text {diester }}(\%)^{\mathrm{d}}$ \\
\hline 40 & $30.1 \pm 3.4$ & 8.8 & 21.3 & $25.1 \pm 1.4$ & 14.9 & 10.2 \\
\hline 50 & $30.7 \pm 1.8$ & 8.8 & 21.9 & $27.1 \pm 0.2$ & 14.6 & 12.5 \\
\hline 60 & $32.8 \pm 0.5$ & 8.8 & 24.0 & $29.0 \pm 1.1$ & 14.1 & 14.9 \\
\hline
\end{tabular}

\footnotetext{
${ }^{\mathrm{a}}$ The hydrogels were purified in milli-Q water $(\mathrm{pH}-7)$, at $4{ }^{\circ} \mathrm{C}$ for 10 days, changing the water daily. Afterwards, the hydrogels were dried at room temperature under vacuum until constant weight was attained, and analyzed by FTIR.

${ }^{\mathrm{b}}$ Defined as the number of DVA molecules incorporated into dextran through single or double ester bonds per 100 dextran glucopyranoside residues (average $\pm \mathrm{SD}, n=3$ ).

${ }^{\mathrm{c}}$ Defined as the number of DVA molecules incorporated into dextran through a single ester bond containing both a free carboxyl end group per 100 dextran glucopyranoside residues (as determined by FTIR; see materials and methods) and a calculated vinyl ester end group. The calculated value of 8.8 represents the number of DVA molecules incorporated into dextran containing a terminal vinyl ester moiety per 100 glucopyranoside residues. This number was obtained from a $6000 \mathrm{Da}$ dextran substrate reacted with DVA (as was done with the 70,000 Da dextran) for which accurate NMR vinyl group analysis was performed because the smaller dextran substrate did not form a gel.

${ }^{\mathrm{d}}$ Defined as the difference between DS and $\mathrm{DS}_{\text {monoester }}$.
} 
and the reaction initiated by adding $300 \mathrm{mg}$ of Proleather. The reaction mixtures were shaken at $50{ }^{\circ} \mathrm{C}$ and $250 \mathrm{rpm}$ for $72 \mathrm{~h}$. In the reaction mixtures that did not gel, the solutions were centrifuged at $4000 \mathrm{rpm}$ for $10 \mathrm{~min}$ and the supernatants mixed with water $(3: 7, \mathrm{v} / \mathrm{v})$ and dialyzed (MWCO 50,000; Spectrum, CA) against $\mathrm{HC} 1$ aqueous solution $\mathrm{pH} 3.0$ for 7 days and then for three additional days against milli-Q water at $4{ }^{\circ} \mathrm{C}$. Afterwards the aqueous solutions were freeze-dried for $48 \mathrm{~h}$ (isolated yields between $60 \%$ and $85 \%$ ). In reaction mixtures that did gel, the resulting gels were separated from the glass beakers and immersed in milli-Q water, at $4{ }^{\circ} \mathrm{C}$ for 10 days, changing the water daily. Afterwards, the gels were cut in disc-shape sections with a thickness of $0.4-0.6 \mathrm{~cm}$, dried at room temperature under vacuum in the presence of phosphorous pentoxide until constant weight was attained (isolated yields between $72 \%$ and $87 \%$ ). The degree of substitution (DS) of dextran derivatives (either in the gel or non-gel form) was determined by FTIR, taking into account the ratio of the absorption bands at $1730 \mathrm{~cm}^{-1}($ ester, $v(\mathrm{C}=\mathrm{O})$ ) and $760 \mathrm{~cm}^{-1}$ (dextran). DS is defined as the number of DVA molecules incorporated into dextran through single or double ester bonds per 100 dextran glucopyranoside residues. The ratio $\left(A_{1730} / A_{760}\right)$ values were then converted into DS using a calibration curve of dextran, $M_{w}=6 \mathrm{kDa}$, derivatized with different concentrations of DVA (water-soluble compounds), where DS was calculated using ${ }^{1} \mathrm{H}$ NMR spectroscopy. In this case, $\mathrm{DS}=[(7 \times x) /(4 \times y)] \times 100$, where $x$ is the integral of the adipate protons in the range of $\delta 2.47-1.64 \mathrm{ppm}$ and $y$ is the integral of all dextran protons between $\delta 5.56$ and $3.20 \mathrm{ppm}$.

\subsection{Chemical synthesis of dextran-DVA}

Dextran $(1 \mathrm{~g}, 1.0 \mathrm{~mm})$ and different concentrations of DVA $(0.041-0.41 \mathrm{M})$ were dissolved in $15 \mathrm{~mL}$ DMSO and the reaction commenced by adding 4-DMAP $(200 \mathrm{mg})$. The reaction mixtures were shaken at $50{ }^{\circ} \mathrm{C}$ and $250 \mathrm{rpm}$ for $72 \mathrm{~h}$. In the reaction mixtures that gelled, the resulting products were separated from the glass beakers and immersed in milli-Q water adjusted to $\mathrm{pH} 3.0$, for 10 days at $4{ }^{\circ} \mathrm{C}$, changing the water daily. Afterwards, the hydrogels were dried at room temperature, under vacuum, until constant weight was attained.

\subsection{SEM and MIP analyses}

Swollen dextran-DVA hydrogels were quickly frozen in a glass container using liquid nitrogen and freezedried for $48 \mathrm{~h}$. Fractured pieces of $0.6-0.9 \mathrm{~cm}$ in length, corresponding to half-diameter of each hydrogel, were mounted into aluminium stud and gold coated by plasma vapor deposition. The surface and cross-section of the gels were recorded by a field emission electron microscope (JEOL model JSM-5310) at $15-20 \mathrm{kV}$. Mercury porosimetry (Micromeritics Poresizer 9320) was used to determine the bulk density, skeletal density, porosity, and pore size distribution. All samples were degassed before analysis at a vacuum pressure below $50 \mathrm{mmHg}$. High pressure runs (from 25 to 30,000 psia) were made with an equilibration time of $20 \mathrm{~s}$ and a maximum intrusion volume of $0.05 \mathrm{~mL} / \mathrm{g}$. The porograms (intruded volume versus pressure) obtained were converted into pore diameter distribution curves (cumulative and differential) according to the Washburn equation [17], $p d=-4 r \cos \theta$, where $p$ is the pressure required to force mercury into a pore of entry diameter $d, r$ is the surface tension $\left(485 \mathrm{dyncm}^{-1}\right)$, and $\theta$ is the contact angle between mercury and the sample $\left(130^{\circ}\right)$. The porosity of hydrogels was calculated from the equation: porosity $=[($ skeletal density-bulk density $) /$ skeletal density] $\times 100$.

\subsection{In vitro degradation studies}

Dried dextran-DVA hydrogels, accurately weighed $\left(W_{\mathrm{i}}\right)$, were immersed in $10 \mathrm{~mm}$ phosphate buffer saline (PBS) $\mathrm{pH}$ 7.4. At different times they were removed, lyophilized on a freeze drier (FTS System, NY) for $24 \mathrm{~h}$ and weighed $\left(W_{\mathrm{t}}\right)$. After $W_{\mathrm{t}}$ determination, either swelling ratio $\left(\mathrm{SR}=\left(W_{\mathrm{s}}-W_{\mathrm{t}}\right) / W_{\mathrm{t}}\right.$ where $W_{\mathrm{s}}$ is the weight of swollen hydrogel and $W_{\mathrm{t}}$ is the weight of dried hydrogel) or mass remaining $\left[\left(W_{\mathrm{t}} / W_{\mathrm{i}}\right) \times 100\right]$ were calculated. Then, the DS and $\mathrm{DS}_{\text {monoester }}$ (defined as the number of DVA molecules incorporated to dextran through single ester bonds, and hence retaining a carboxylic moiety, per 100 dextran glucopyranoside residues) were determined by FTIR spectroscopy. The $\mathrm{DS}_{\text {monoester }}$ was calculated as the ratio between the absorbance at $1560 \mathrm{~cm}^{-1}$ (stretching of the $\mathrm{COO}^{-}$ group) and at $760 \mathrm{~cm}^{-1}$ (dextran). The ratio was then converted into $\mathrm{DS}_{\text {monoester }}$ after using a calibration curve of sodium adipate and dextran in different molar ratios.

\subsection{In vivo biocompatibility studies}

European community guidelines (No. 86/609/CE; corresponding to decree No. 1005/92 of Portuguese legislation) for the care and use of laboratory animals were observed. Male Wistar rats (8-12-week old) were anesthetized, with $\operatorname{Ketalar}^{\circledR}\left(50 \mathrm{mg} \mathrm{kg}^{-1}\right.$, Parke-Davis) and an area of the front was shaved and washed with Betadine ${ }^{\circledR}$. Two incisions along the spine $(\mathrm{ca} .1 \mathrm{~cm}$ in length) were made and two subcutaneous pockets were created. The hydrogels $(3 \times 2 \mathrm{~mm}, 3 \mathrm{~mm}$ thickness $)$, previously UV-sterilized and swollen in citrate-phosphate $\mathrm{pH}$ 5.0, were placed into the pocket away from the incision (ca. $0.5 \mathrm{~cm}$ ) and the skin was closed with 
Mersilk ${ }^{\circledR}$ non-absorbable suture (3 Øs, Ethicon). The area was washed with Betadine ${ }^{\circledR}$ dermic solution and the rats kept warm with a heating pad for $1 \mathrm{~h}$ after the surgical procedure and finally transferred to a cage. Three rats were used for each time point. As a control, subcutaneous pockets were made without implants. At certain times, the rats were sacrificed and the implants with surrounding tissue where carefully dissected and fixed in $4 \%(\mathrm{v} / \mathrm{v})$ neutral buffered formalin, for at least 3 days. The blocks were sliced perpendicular or crosssectional to the implanted hydrogels. The implant and adjacent tissue were oriented and placed in processing cassettes, taken through a graded ethanol series (Shandon Citadel 1000) and embedded in paraffin. The samples were then sectioned using a microtome (Shandon Retraction AS 325), and finally deparaffinized and stained either with hematoxylin/eosin, periodic acid-schiff, or Masson's trichrome [18]. Multiple photographs were taken of each hydrogel and the surrounding tissues using a Nikon microscope (Eclipse E 600) with a Nikon camera (FOX-35). The tissue response was rated by two persons.

\section{Results and discussion}

\subsection{Enzymatic synthesis of dextran-based hydrogels}

Native dextran is soluble in water or very polar organic solvents such as DMSO; however, only in the latter can enzyme-catalyzed transesterification of dextran be performed without undesirable ester hydrolysis. Eleven enzymes (Table 1 of supplementary Material), chosen from a group of hydrolases that are known to catalyze the acylation of simple sugars or other polysaccharides in organic media [12,16,19-21], were screened for their abilities to catalyze the acylation of dextran $\left(M_{\mathrm{w}}=70,000\right)$ with DVA (Fig. 1A). Three of the enzymes gave appreciable conversion, with an alkaline protease from B. subtilis (Proleather FG-F) and two lipases (from C. rugosa and P. cepacia) yielding $>58 \%$ conversion of the dextran. Furthermore, each of these reactions resulted in the formation of a gel, which did not form in control reactions in the absence of enzyme or in the presence of the aforementioned enzymes in the absence of DVA. FTIR spectra (Fig. 1
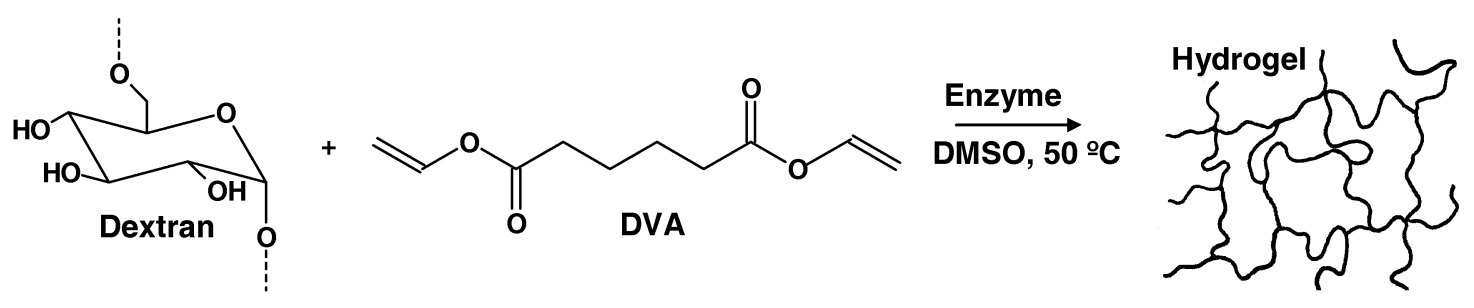

(A)
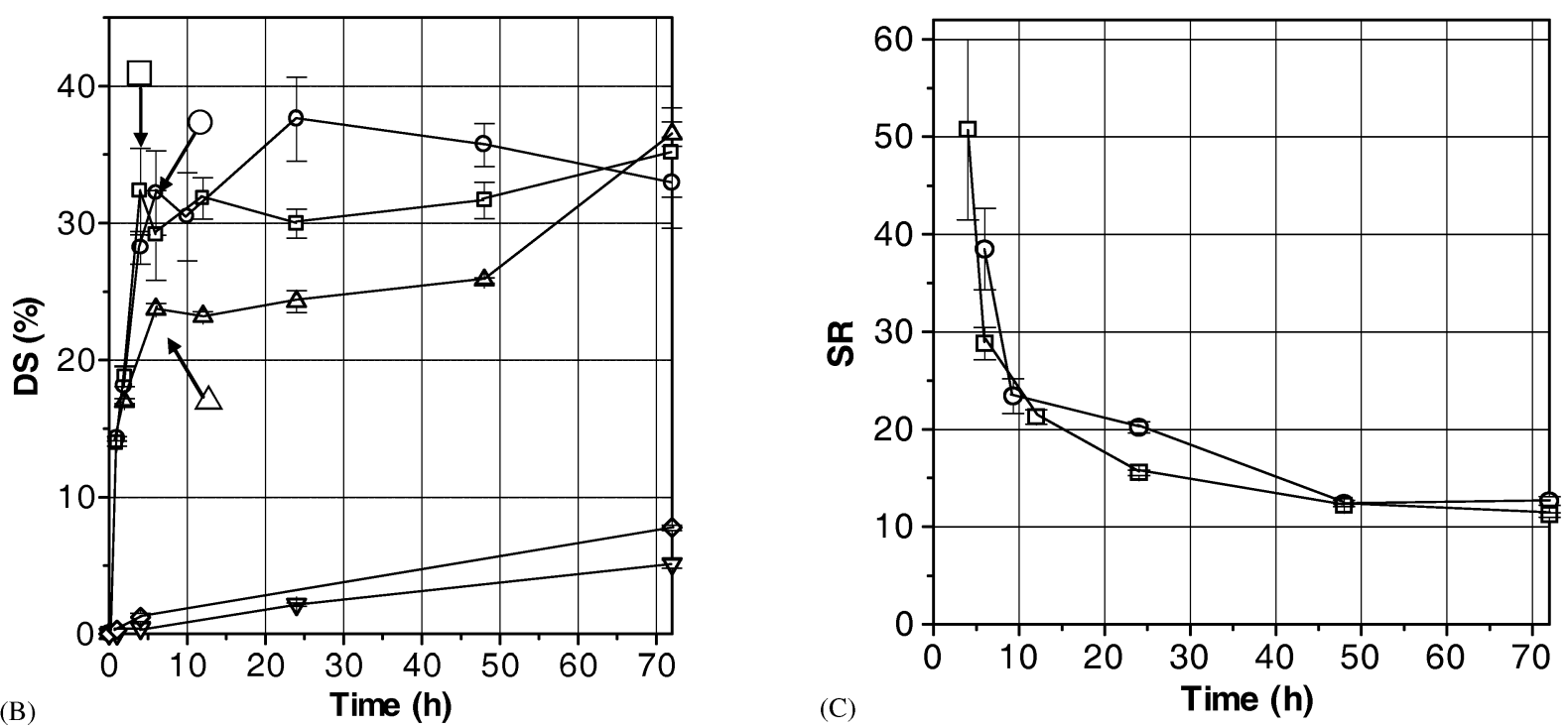

Fig. 1. Proleather-catalyzed acylation of dextran with DVA. (A) Synthesis scheme. (B) DS as a function of time for the reaction of dextran with DVA (initial molar ratio of DVA to dextran glucopyranose residues of $50 \%)$ in the presence of active Proleather $[10 \mathrm{mg} / \mathrm{mL}(\triangle), 20 \mathrm{mg} / \mathrm{mL}(\bigcirc)$ and $30 \mathrm{mg} / \mathrm{mL}(\square)]$ and in the absence of enzyme $(\nabla)$ or in the presence of thermally deactivated Proleather $(\diamond)(10 \mathrm{mg} / \mathrm{mL})$. The arrows in the graph indicate the reaction times at which gelation was observed. (C) Swelling ratio (SR) measurements of dextran-DVA hydrogels prepared in the timecourse transesterification reactions [Proleather concentration of $20 \mathrm{mg} / \mathrm{mL}(O)$ and $30 \mathrm{mg} / \mathrm{mL}(\square)$ ] following extensive washing procedures in milli-Q water for 10 days at $4{ }^{\circ} \mathrm{C}$. 
of Supplementary Material) of the gels confirmed the presence of carbonyl groups (peak at $1730 \mathrm{~cm}^{-1}$ ) arising from the DVA molecules attached to dextran. To complement these results, $\mathrm{CP} / \mathrm{MAS}{ }^{13} \mathrm{C}$ NMR spectroscopy was undertaken (Fig. 1 of Supplementary Material), and provided evidence of the carbonyl carbon at $\delta 175.8 \mathrm{ppm}$ and the adipate carbons at $\delta 32.5$ and $25.9 \mathrm{ppm}$ further confirming the transesterification of dextran with DVA.

All three enzymes were active in the organic solvent, which was surprisingly given the well-known deactivation of enzymes in neat DMSO [22,23]. To confirm that the transesterification reaction was indeed enzymatic, several control reactions were performed using Proleather as the most reactive enzyme. Limited spontaneous reaction (conversion $<15 \%$ with no gel formation) was observed in the absence of enzyme or with thermally deactivated Proleather over a period of $72 \mathrm{~h}$ (Fig. 1B). Enzyme pre-inactivated by the serine protease inhibitor phenylmethanesulfonyl fluoride (PMSF) also gave minimal reactivity and again no gel formation was observed. The enzyme activity was not due to an underlying contaminant in the commercial preparation, as SDS-PAGE revealed only one significant protein band (data not shown).

The ability of Proleather to remain active while dissolved in DMSO was strongly dependent on the nature of the enzyme preparation. The commercial Proleather preparation contains only ca. 13\% (w/w) protein being the remaining fraction formed by maltose (data provided by manufacturer). Upon dialysis to increase the protein content to $18 \%(\mathrm{w} / \mathrm{w})$ the dextran conversion was reduced 1.6-fold compared to the crude enzyme preparation. Proleather was also active in DMSO on simple compounds related to dextran, including the simple sugar $O$-methyl- $\alpha$-D-glucoside. Interestingly, as the sugar size is increased to maltose and maltotriose, Proleather activity in DMSO increased (Table 2 of Supplementary Material). Specifically, the activity of Proleather was over 20-fold higher on maltotriose than on $O$-methyl- $\alpha$-D-glucoside. While it is difficult to compare directly the reactivity of Proleather on simple sugars versus polysaccharides, these results nonetheless suggest that the presence of sugars of increasing size (including the polysaccharide dextran itself) help stabilize Proleather in the soluble state in DMSO and may play a role in enabling transesterification reactions to be performed.

\subsection{Physical characterization of enzymatically generated dextran hydrogels}

The time course of Proleather-catalyzed dextran acylation is depicted in Fig. 1B, where a rapid increase is observed in DS. This is concomitant with a decrease in the equilibrium swelling ratio of the hydrogels (Fig. 1C), which continues even past the point of an observable increase in the extent of acylation, and a substantial decrease in average pore diameter from ca. $21-6 \mu \mathrm{m}$, at 24 and $72 \mathrm{~h}$ of reaction time, according to scanning electron microscopy (SEM) results (data not shown). This is likely due to the rapid acylation of dextran with DVA followed by a slower intra- and/or intermolecular reaction of the second vinyl ester group of DVA with another part of the dextran chain or other dextran chains to form adipate crosslinks.

The elastic modulus of hydrogels ranged from $1.4 \mathrm{kPa}$ for hydrogels prepared with a DS of $20 \%$ to $5.8 \mathrm{kPa}$ for hydrogels prepared with a DS of $47 \%$, as measured by an indentation method [19]. Interestingly, the hydrogels prepared biocatalytically show a higher elastic modulus for a given swelling ratio than dextran-based hydrogels synthesized by others chemically. For example, for hydrogels with calculated polymer volume fractions of $0.04-0.05$, the elastic modulus of dextran biocatalytic hydrogels is twice as high than that of a gel obtained via chemical crosslinking with hexamethylenediisocyanate [24] (4.9 versus $2.2 \mathrm{kPa}$ ) and 4-fold higher than dextranmethacrylate hydrogels [25] (2.6 versus $0.6 \mathrm{kPa})$. For a more direct comparison, dextran was acylated

Table 2

Characteristics of swollen dextran-DVA hydrogels with different DS as measured by MIP

\begin{tabular}{|c|c|c|c|c|c|}
\hline Sample & DS $(\%)$ & $\begin{array}{l}\text { Volume of mercury } \\
\text { intruded }(\mathrm{mL} / \mathrm{g})\end{array}$ & $\begin{array}{l}\text { Average pore diameter } \\
(\mu \mathrm{m})\end{array}$ & Pore size distribution & $\begin{array}{l}\text { Porosity } \\
(\%)^{\mathrm{a}}\end{array}$ \\
\hline Biocatalytic hydrogels & $\begin{array}{l}28 \\
30 \\
31 \\
47\end{array}$ & $\begin{array}{l}8.98 \\
8.17 \\
5.12 \\
4.86\end{array}$ & $\begin{array}{l}2.0^{\mathrm{b}} \\
1.7^{\mathrm{b}} \\
0.72^{\mathrm{b}} \\
0.38^{\mathrm{b}}\end{array}$ & $\begin{array}{l}3.5-0.18^{\mathrm{d}} \\
3.2-0.21^{\mathrm{d}} \\
1.0-0.21^{\mathrm{d}} \\
0.65-0.17^{\mathrm{d}}\end{array}$ & $\begin{array}{l}89.0 \\
86.3 \\
82.8 \\
80.1\end{array}$ \\
\hline $\begin{array}{l}\text { Chemical } \\
\text { hydrogels }\end{array}$ & $\begin{array}{l}27 \\
29\end{array}$ & $\begin{array}{l}1.09 \\
1.01\end{array}$ & $\begin{array}{l}25 / 0.3^{\mathrm{c}} \\
35 / 0.15^{\mathrm{c}}\end{array}$ & $\underline{-}^{\mathrm{c}}$ & $\begin{array}{l}67.8 \\
66.5\end{array}$ \\
\hline
\end{tabular}

\footnotetext{
${ }^{\mathrm{a}}$ Calculated as ((skeletal density-bulk density)/skeletal density $) \times 100$.

${ }^{\mathrm{b}}$ Unimodal distribution: value corresponding to the mode of the peak.

${ }^{\mathrm{c}}$ Bimodal distribution: values corresponding to the mode of the peaks. See Fig. 2 for pore size distribution.

${ }^{\mathrm{d}}$ Determined at $1.5 \mathrm{~mL} / \mathrm{g}$ in the figure of $\log$ differential intrusion versus pore diameter.
} 
chemically with DVA using 4-DMAP [25] as catalyst in DMSO at $50{ }^{\circ} \mathrm{C}$. Hydrogel formation required $40 \%$ DS, in contrast to $20 \%$ needed for gel formation in the enzymatic process. Even at $40 \%$ DS, the chemically generated hydrogels were fragile and easily fragmented preventing modulus determination.

Because the biocatalytic hydrogels were mechanically stronger than the chemical ones, our results suggest that Proleather catalysis favors the formation of a greater number of intermolecular crosslinks as compared to the chemical route. The low number of intermolecular crosslinks in the 4-DMAP-catalyzed reaction is likely due to the lower efficiency of this catalyst to promote the attachment of both of the terminal vinyl ester groups of DVA into dextran. Indeed, the biocatalytically generated hydrogels contained up to twice as many diester adipate crosslinks (at the expense of the less productive monoester linkages) than the chemically generated hydrogels. This is clearly seen by inspection of Table 1 , where the $\mathrm{DS}_{\text {diester }}$ content in the biocatalytically generated hydrogels are on average ca. 2.5-fold higher

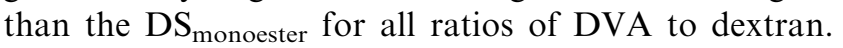
Conversely, the chemically generated hydrogels favor the $\mathrm{DS}_{\text {monoester }}$ by ca. 1.2-fold. Many of the diester crosslinks are likely to be intermolecular, and hence the biocatalytic hydrogels are stronger than those prepared chemically at the same total degree of substitution.

Differences between the enzymatically and chemically (DMAP catalyzed) synthesized dextran-DVA hydrogels were further highlighted using SEM analysis of the resulting gel networks (Fig. 2). The biocatalytic dextran hydrogels had more uniform pore sizes than those of chemically prepared hydrogels. The enhanced structural organization of biocatalytic hydrogels was also confirmed by mercury intrusion porosimetry (MIP) analysis (Fig. 2E). The hydrogels showed a unimodal distribu- tion of pores with average diameters from 0.4 to $2.0 \mu \mathrm{m}$ (Table 2). The average pore diameter decreased as the DS of hydrogel increased, which was expected given the higher crosslink density at higher DS values. The sharp peaks of the porograms show that the pore size distribution is narrow and relatively homogeneous. In contrast, chemically synthesized dextran-DVA hydrogels showed a bimodal distribution of pores and therefore were relatively heterogeneous, with the majority of pores above $25 \mu \mathrm{m}$ in size (Fig. $2 \mathrm{~F}$ and Table 2). In addition, as clearly shown by the low content of mercury intruded (Fig. 2F and Table 2), these hydrogels present a lower number of pores than biocatalytic hydrogels. Finally, the porosity values on biocatalytic hydrogels were above $80 \%$ and therefore higher than those obtained on dextran-DVA hydrogels synthesized chemically (porosity values below $68 \%$ ). The high porosity values on biocatalytic hydrogels show that hydrogels are formed by an interconnected structure, which may make these networks attractive for tissue engineering applications where porosities above $80 \%$ are desired for tissue integration [26].

The structural organization of biocatalytic dextranDVA hydrogels is also distinct from chemically synthesized dextran-based hydrogels reported in the literature. For example, Kim and Chu [10] showed a bimodal distribution of pore sizes either in mesopore or macropore regions between the surface and interior of dextran-methacrylate hydrogels. Such heterogeneity was explained by different degrees of crosslinking during photopolymerization of the dextran-methacrylate hydrogel precursor, caused by a differential UV-penetration through the material [10]. In our case, the homogeneity in dextran-DVA hydrogels obtained enzymatically may be at least partly due to the regioselectivity achieved in the enzymatic process [19] and the
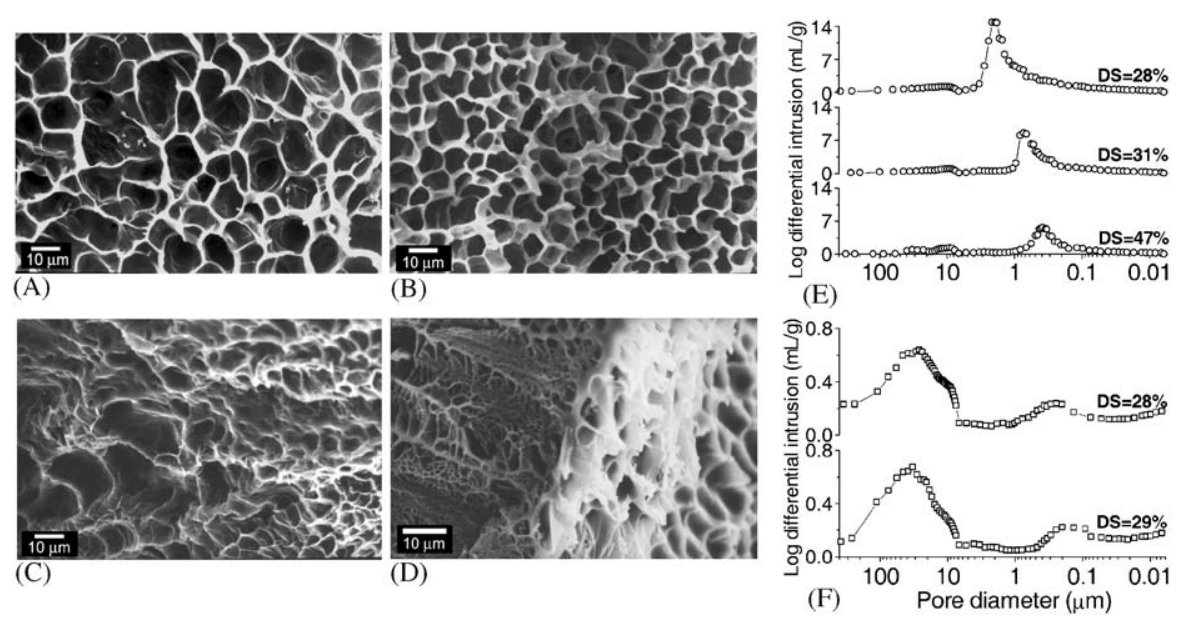

Fig. 2. Scanning electron micrographs (SEM) and mercury intrusion porosimetry distribution from dextran-based hydrogels. (A-D) SEM from the surface of swollen dextran-DVA hydrogels in $10 \mathrm{~mm}$ citrate-phosphate $\mathrm{pH} 5.0$, after being previously dried: DS $28 \%$ (A), 30\% (B), 27\% (C), 29\% (D). Hydrogels were obtained either enzymatically (A,B) or chemically (C,D). (E,F) Plot of pore size distribution (log differential intrusion) against diameter of dextran-DVA hydrogels obtained enzymatically $(O)$ or chemically $(\square)$. 
uniform crosslinking of the dextran promoted by a homogeneous distribution of the biological catalyst.

\subsection{Biocompatibility and degradation studies}

Biocompatibility of the dextran-based hydrogels was assessed via subcutaneous implantation in rats, using hydrogels of DS values ranging from $28 \%$ to $47 \%$. The intensity of the inflammatory response to these foreign implants was monitored histologically and qualitatively interpreted. Representative light micrographs of dex-
tran-DVA DS $31 \%$ and DS $47 \%$ hydrogels implanted subcutaneously are presented in Fig. 3. In general, the dextran-based hydrogels appeared to show good in vivo biocompatibility at least under the limited conditions of this study. The inflammatory response (during the first 5/10 days; Figs. 3A and B) was mild with all hydrogels. Granulocyte and lymphocyte cells, as well exudate and fibrin, completely disappeared by day 10 . The wound healing response to the implants consisted initially of macrophages eroding the hydrogel surface, fibroblasts depositing collagen into the region of the implant, and
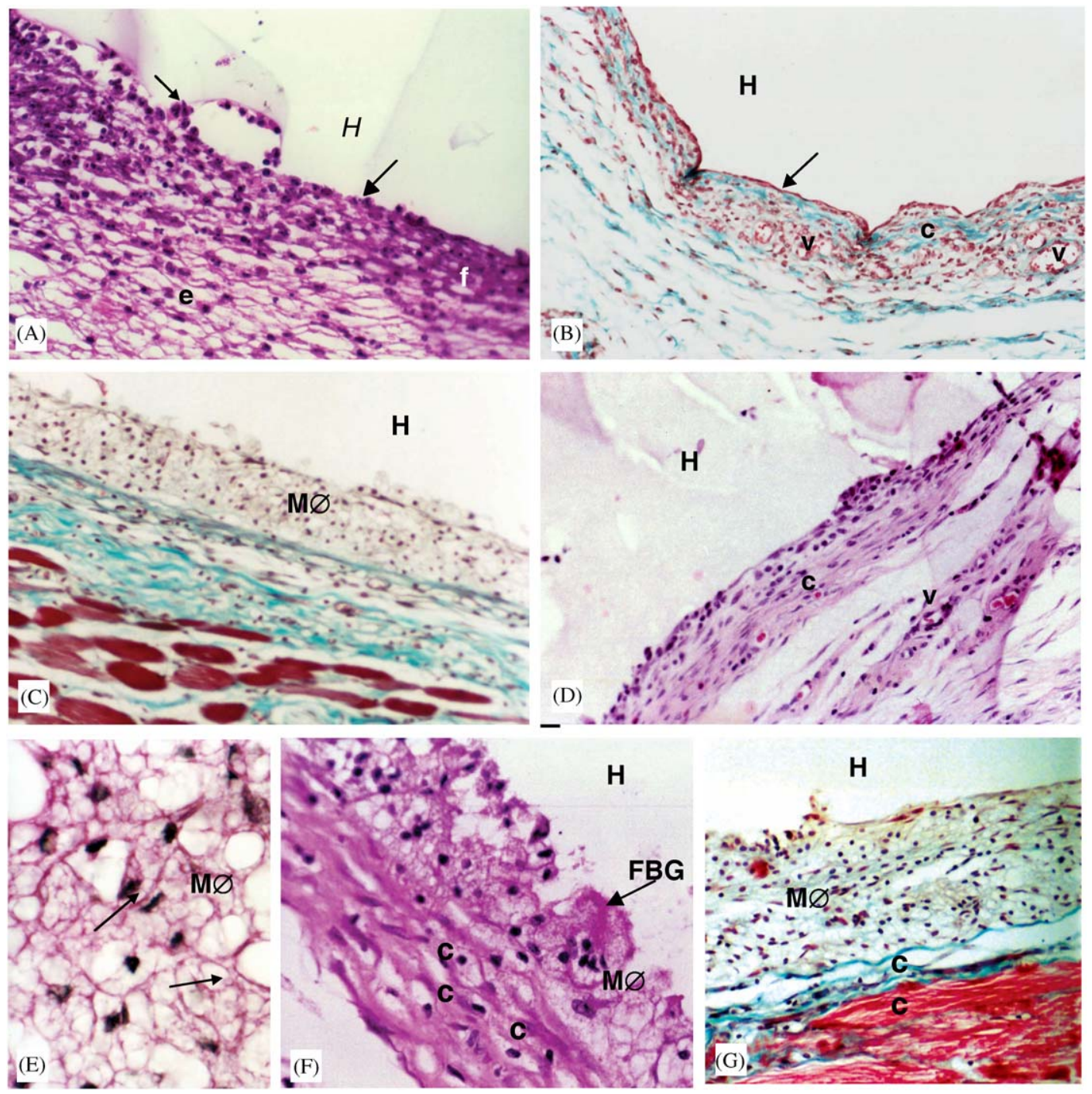

Fig. 3. Hydrogel implantation studies. Representative light micrographs of dextran-DVA DS 31\% (A-E) and DS 47\% (D,F,G) hydrogels implanted subcutaneously and surrounding tissue at different times, stained with hematoxylin/eosin (A,D,F), Masson's trichrome (B,C,G) and periodic acidschiff (E). (A) At day 2, a moderate inflammatory reaction is observed surrounding the hydrogel DS $31 \%$ (H): granulocytes (arrow), mainly neutrophils, adhered to the hydrogel and they were surrounded by fibrin (f) and exudate (e). (B) At day 5, a cell layer (arrow) formed essentially by fibroblasts surrounded the hydrogel DS $31 \%$, while collagen (c) was found underneath the cell layer. Newly blood vessels (v) were also present at the surrounding tissue. (C,D) At day 10, the hydrogel DS 31\% was surrounded by several layers of hydrogel-containing macrophages (MØ), which were involved by fibroblast cells and collagen. These macrophages were not observed in hydrogel DS $47 \%$ (D). (E) At day 20, the hydrogel DS $31 \%$ was completely degraded and macrophages (MØ) containing internalised hydrogel particles (arrows) were observed at the place originally occupied by the hydrogel. (F,G) At day 40, the hydrogel DS 47\% undergoes degradation and macrophages (MØ) as well foreign body cells (FBG) are observed surrounding the hydrogel. These cells were surrounded by collagen (c), which was either $(\mathrm{F})$ or not $(\mathrm{G})$ organised in a minor fibrous capsule. Magnifications are $100 \times$ for $\mathrm{A}$ and $\mathrm{F}, 50 \times$ for $\mathrm{B}-\mathrm{D}$ and $\mathrm{G}$, and $250 \times$ for $\mathrm{E}$. 
the presence of few foreign body giant (FBG) cells formed by fusion of macrophages, particularly in high DS dextran-DVA hydrogels. These tissue responses are consistent with those observed in other biocompatible hydrogel implants (e.g., crosslinked gelatin and methacrylated dextran hydrogels) $[15,27]$.

The influence of DS was clearly evident in subcutaneous implantation. Hydrogel-containing macrophages were observed at 5,10 , and 40 days post-implantation for hydrogels with DS values of $28 \%, 31 \%$, and $47 \%$, respectively. These cells contained hydrogel particles, as confirmed by periodic acid-Schiff staining (Fig. 3E), which suggests a phagocytosis process. As expected, this phenomenon begins earlier for hydrogels with lower DS, primarily because of the smaller number of crosslinks and the more rapid degradability. FBG cells were observed mainly in the hydrogel with a DS of $47 \%$ (Fig. 3F). The high number of FBG cells in this highly crosslinked network is likely due to its rough surface [27]. A layer of collagen-depositing fibroblasts was observed surrounding the macrophage and FBG cells. This collagen layer begins to organize visually into a fibrous capsule by day 10 , both with hydrogels DS $31 \%$ and $47 \%$ (hydrogel DS $28 \%$ was degraded by this time). For hydrogel DS $31 \%$ the network subsequently degrades (see below), and therefore, no mature fibrous capsule is formed, while for hydrogel DS $47 \%$ a discontinuous fibrous capsule is observed (Figs. 3F and $\mathrm{G})$. In this last case, in most regions the collagen strands are low in number and loosely organized (Fig. $3 \mathrm{G})$ yielding little or no clear boundary between the hydrogel implant and the surrounding tissue. The lack of fully intact fibrous capsule formation is relatively unique in comparison to other non-degradable [14,15] and degradable [27,28] hydrogels, which favor the formation of fibrous capsule when implanted in vivo. This also compares favorably with other dextran-based hydrogels described elsewhere [29], where a continuous and compact fibrous capsule was observed after 4 weeks post-implantation. The incomplete fibrous capsule formation in the dextran-DVA gels is critical in supporting ultimate gel integration within the surrounding tissue.

Hydrogels DS $28 \%, 31 \%$, and $47 \%$ were degraded between 5 and 10 days, 20, and 30 days, and $>40$ days, respectively. It is likely that the hydrogel degradation is mainly caused by the hydrolysis of the ester linkage of the crosslink molecules, as observed in the in vitro studies. Fig. 4A shows the swelling behavior of dextranDVA hydrogels as a function of time, when incubated in $10 \mathrm{mM}$ PBS at $\mathrm{pH}$ 7.4. The hydrogels showed a progressive swelling in time, which in case of dextranDVA DS $28 \%$ and $31 \%$ was followed by a dissolution phase (in case of hydrogels DS $47 \%$, further time was needed to accomplish dissolution). The increased swel-
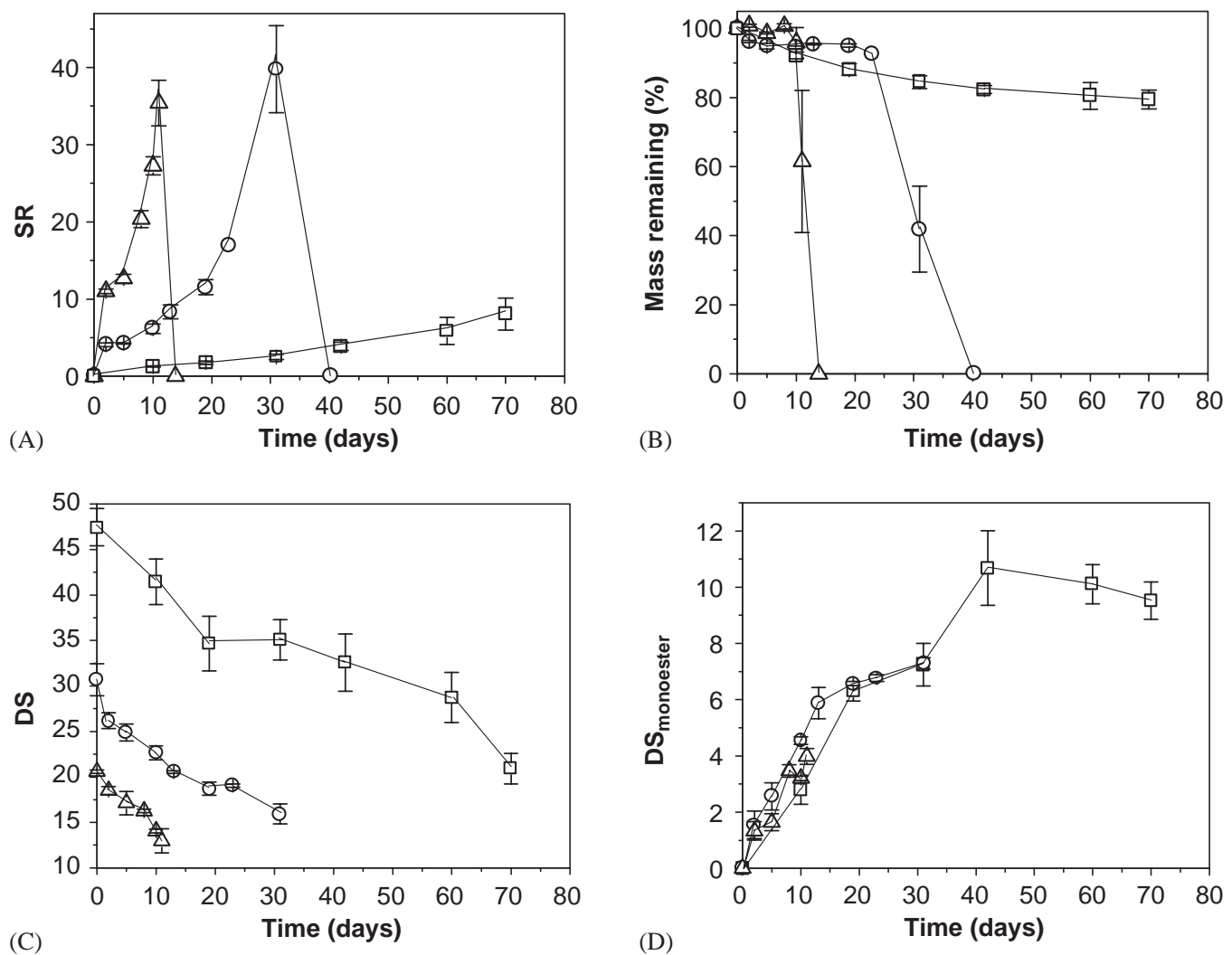

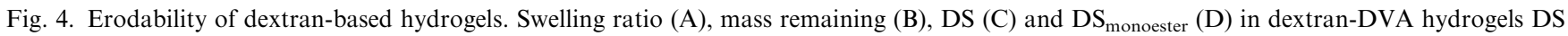
$28 \%(\triangle), 31 \%(\mathrm{O})$ and $47 \%(\square)$ as a function of time, when immersed in $10 \mathrm{mM} \mathrm{PBS} \mathrm{pH} 7.4$, at $37^{\circ} \mathrm{C}$ (average $\pm \mathrm{SD}, n=3$ ). 
ling is likely a consequence of the hydrolysis of crosslinks (adipate groups) in the hydrogel network (as depicted by a loss in DS with time in Fig. 4C) and not dextran, which is stable at this $\mathrm{pH}$ [30]. When crosslinks in the network are cleaved, the network swells and imbibes more water. Furthermore, as the adipate groups hydrolyze to yield single ester bonds onto the dextran and free carboxyl moieties (Fig. 4D), the ionized carboxyl groups will increase the swelling behavior of the hydrogel upon Donnan equilibrium is achieved. As expected, hydrogels with higher DS and higher number of intermolecular crosslinks tend to hydrolyze slower than ones with lower DS. The mass loss of dextranDVA hydrogels was also monitored as a function of time. As shown in Fig. 4B, the mass loss was minimal for SR values below $30(<10 \%$ for dextran-DVA DS $28 \%$ and $31 \%$ hydrogels), albeit dramatic when hydrogels achieved their maximum swelling (SR of 35-40). In this last case, dextran chains bear few crosslinks per chain and hydrogels start to disintegrate quickly. This indicates that the hydrolysis of dextran-DVA hydrogels occurs through a bulk erosion mechanism. A similar hydrolysis mechanism was observed for poly(glycolic acid)/poly(lactic acid) polymers [6] and poly(propylene fumarate-co-ethylene glycol) hydrogels [28], among others.

\section{Conclusions}

We have shown that selected enzymes are able to catalyze the synthesis of dextran-based hydrogels in a single step, enabling the formation of macroporous, structurally organized hydrogels with superior mechanical properties to dextran-based hydrogels obtained chemically. These hydrogels are degradable at physiologic $\mathrm{pH}$, do not form substantial fibrous capsule when implanted subcutaneously in rats, and may find applications as cell-carriers (scaffolds) or implantable biomolecule delivery vehicles. Moreover, the technique employed is simple, involves commercially available enzymes and reagents, and should be suitable with a wide range of abundant polysaccharides.

\section{Acknowledgments}

We are grateful for the financial support of Fundação para a Ciência e a Tecnologia (Praxis XXI, BD/18456/ 98) to L.F. and the Biotechnology Research and Development Corporation to J.S.D. We thank Dr. Andrade Ramos and Dr. Margarida Figueiredo for assistance with mercury intrusion porosimetry analyses, and Ana Rafael for assistance with in vivo biocompatibility studies.

\section{Appendix A. Supplementary data}

The online version of this article contains additional supplementary data. Please visit doi:10.1016/j.biomaterials.2004.11.051.

\section{References}

[1] Lee KY, Peters MC, Anderson KW, Mooney DJ. Controlled growth factor release from synthetic extracellular matrices. Nature 2000;408:998-1000.

[2] Zhu G, Mallery SR, Schwendeman SP. Stabilization of proteins encapsulated in injectable poly(lactide-co-glycolide). Nature Biotechnol 2000;18:52-7.

[3] Shea LD, Smiley E, Bonadio J, Mooney DJ. DNA delivery from polymer matrices for tissue engineering. Nature Biotechnol 1999;17:551-4.

[4] Griffith LG, Naughton G. Tissue engineering-current challenges and expanding opportunities. Science 2002;295:1009-14.

[5] Lee KY, Mooney DJ. Hydrogels for tissue engineering. Chem Rev 2001;101:1869-79.

[6] Wong WH, Mooney DJ. Synthesis and properties of biodegradable polymers used as synthetic matrices for tissue engineering. In: Atala A, Mooney DJ, editors. Synthetic biodegradable polymer scaffolds. Boston: Birkhäuser; 1997. p. 49-82.

[7] Holmes TC. Novel peptide-based biomaterial scaffolds for tissue engineering. TIBTECH 2002;20:16-21.

[8] Mehvar R. Dextrans for targeted and sustained delivery of therapeutic and imaging agents. J Control Rel 2000;69: $1-25$.

[9] Kim S-H, Chu C-C. Synthesis and characterization of dextranmethacrylate hydrogels and structural study by SEM. J Biomed Mater Res 2000;49:517-27.

[10] Kim S-H, Chu C-C. Pore structure analysis of swollen dextranmethacrylate hydrogels by SEM and mercury intrusion porosimetry. J Biomed Mater Res (Appl Biomater) 2000;53: 258-66.

[11] Meyvis T, De Smedt S, Stubbe B, Hennink W, Demeester J. On the release of proteins from degrading dextran methacrylate hydrogels and the correlation with the rheologic properties of the hydrogels. Pharm Res 2001;18:1593-9.

[12] Patil NS, Dordick JS, Rethwisch DG. Macroporous poly(sucrose acrylate) hydrogel for controlled release of macromolecules. Biomaterials 1996;17:2343-50.

[13] Park H, Park K. Biocompatibility issues of implantable drug delivery systems. Pharm Res 1996;13:1770-6.

[14] Loebsack A, Greene K, Wyatt S, Culberson C, Austin C, Beiter R, Roland W, Eiselt P, Rowley J, Burg K, Mooney D, Holder W, Halberstadt C. In vivo characterization of a porous hydrogel material for use as a tissue bulking agent. J Biomed Mater Res 2001;57:575-81.

[15] Cadée JA, Luyn MJA, Brouwer LA, Plantinga JA, van Wachem $\mathrm{PB}$, Groot CJ, Otter W, Hennink WE. In vivo biocompatibility of dextran-based hydrogels. J Biomed Mater Res 2000;50:397-404.

[16] Ferreira L, Gil MH, Dordick JS. Enzymatic synthesis of dextrancontaining hydrogels. Biomaterials 2002;23:3957-67.

[17] Washburn EW. Note on a method of determining the distribution of pore sizes in a porous material. Proc Natl Acad Sci 1921;7:115-6.

[18] Brancroft JD, Stevens A. Theory and practice of histological techniques. Edinburgh: Churchill Livingstone; 1996. p. 99-211.

[19] Martin BD, Linhardt RJ, Dordick JS. Highly swelling hydrogels from ordered galactose-based polyacrylates. Biomaterials 1998;19:69-76. 
[20] Ferreira L, Ramos MA, Gil MH, Dordick JS. Exquisite regioselectivity and transesterification activity enhancement of an immobilized Bacillus subtilis protease. Biotechnol Prog 2002;18:986-93.

[21] Ferreira L, Gil MH, Carvalho R, Geraldes CFGC, Kim D-Y, Dordick JS. Biocatalytic polytransesterification of inulin with divinyladipate. Chem Mater 2002;14:4009-11.

[22] Zaks A, Klibanov AM. Enzymatic catalysis in nonaqueous solvents. J Biol Chem 1988;263:3194-201.

[23] Almarsson Ö, Klibanov AM. Remarkable activation of enzymes in nonaqueous media by denaturing organic cosolvents. Biotechnol Bioeng 1996;49:87-92.

[24] Brøndsted H, Hovgaard L, Simonsen L. Dextran hydrogels for colon-specific drug delivery II. Synthesis and characterization. Eur J Pharm Biopharm 1996;42:85-9.

[25] De Smedt SC, Lauwers A, Demeester J, Van Steenbergen MJ, Hennink WE, Roefs SPFM. Characterization of the network structure of dextran glycidyl methacrylate hydrogels by studying the rheological and swelling behavior. Macromolecules $1995 ; 28: 5082-8$.
[26] Dziubla ID, Torjman MC, Joseph JI, Murphy-Tatum M, Lowman AM. Evaluation of porous networks of poly(2-hydroxyethylmethacrylate) as interfacial drug delivery devices. Biomaterials 2001;22:2893-9.

[27] Kuijpers AJ, Wachem PB, Luyn MJA, Plantinga JA, Engbers GHM, Krijgsveld J, Zaat SAJ, Dankert J, Feijen J. In vivo compatibility and degradation of crosslinked gelatin gels incorporated in knitted Dacron. J Biomed Mater Res 2000;51:136-45.

[28] Suggs LJ, Krishnan RS, Garcia CA, Peter SJ, Anderson JM, Mikos AG. In vitro and in vivo degradation of poly(propylene fumarate-co-ethylene glycol) hydrogels. J Biomed Mater Res 1998;42:312-20.

[29] Ferreira L, Rafael A, Lamghari M, Barbosa MA, Gil MH, Cabrita AMS, Dordick JS. Biocompatibility of chemoenzymatically derived dextran-acrylate hydrogels. J Biomed Mater Res 2004;68A:584-96.

[30] Van Dijk-Wolthuis WNE, Hoogeboom JAM, van Steenbergen MJ, Tsang SKY, Hennink WE. Degradation and release behavior of dextran-based hydrogels. Macromolecules 1997;30: 4639-45. 